\title{
Mathematical Modelling of Diet Planning Problem for Hypertension Patients
}

\author{
Nuridawati Baharom ${ }^{1 *}$, Nur Shamien Alfiera Muhamad Isa ${ }^{2}$ \\ ${ }^{1,2}$ Faculty of Computer and Mathematical Sciences, \\ Universiti Teknologi MARA Perlis Branch, Arau Campus, 02600 Arau, Perlis, Malaysia \\ Corresponding author: *nuridawati@uitm.edu.my \\ Received Date: 20 August 2021 \\ Accepted Date: 1 September 2021 \\ Published Date: 20 September 2021
}

\section{HIGHLIGHTS}

- A balanced diet may provide essential foods for patients with hypertension that help to regulate and lower their blood pressure.

- Linear programming (LP) and integer programming (IP) were used to formulate the mathematical model of diet planning for hypertension patients.

- Identified the food needs for patients with hypertension and the use of LP and IP to achieve an optimal diet.

\begin{abstract}
Hypertension or high blood pressure is also called a "silent killer" that may lead to serious damage to the heart and kidney. The worst case can result in sudden death. Unbalanced diets are one of the risk factors for hypertension. Previous studies have proven that diet plays a significant role in influencing hypertension patient condition. Proper planning on the selection of diets needs to be done to control food intake for this cardiovascular disease patient. This study aims to formulate a mathematical model of diet planning for hypertension patients. Specifically, this study attempts to determine the amount of nutrients need by hypertension patients, to find the cost of the food combination, and to identify the best model between linear programming and integer programming. The research model included 10 types of food groups with 200 variables based on Malaysian recipes and developed a mathematical model using two programming techniques; linear programming and integer programming. The finding showed that the solution provided by the entire programming method has met the constraints and requirements of the food group. The results from the integer programming approach would offer optimal and efficient alternatives to diet planning for patients with hypertension. It can serve as a guideline for hypertension patients on type of food to eat and the correct amount of serving to complete their nutritional plan.
\end{abstract}

Keywords: Linear Programming, Integer Programming, Diet Planning, Mathematical Model, Hypertension, High Blood Pressure 


\section{INTRODUCTION}

Hypertension, also known as high blood pressure, can be defined as systolic blood pressure equal to or above $140 \mathrm{~mm} \mathrm{Hg}$ and/or diastolic blood pressure $90 \mathrm{~mm} \mathrm{Hg}$ or more. Hypertension is a common condition that is high enough for long-term blood stress against the artery to potentially cause health problems, such as cardiovascular disease and stroke. The World Health Organization (2013), has highlighted that hypertension is responsible for at least $45 \%$ of cardiovascular disease deaths and $51 \%$ of stroke deaths. People with hypertension may be asymptomatic for many years before a fatal stroke or heart attack develops. While there is no cure available, the occurrence of hypertension and disease sequelae can be minimized by prevention and management. To avoid the diagnosis of hypertension, people should normalize a healthy lifestyle such as maintaining a healthy body weight, exercising regularly, and following a balanced diet. Dietary habits and choices play a significant role in the quality of life, health, and longevity. A balanced diet involves eating the right amount of food to supply the body with the energy it requires for proper functioning. A well-balanced diet includes foods rich in nutrients from all the food groups. A balanced diet comprises a range of foods that supply our body with vital nutrients such as carbohydrates, proteins, fibers, vitamins, minerals, and fat (Sheng et al., 2017).

A well-developed menu specified for patients with hypertension plays a key role in helping to reduce blood pressure. In addition, eating nutritious foods will help to keep the blood pressure under control. Some foods can trigger and raise blood pressure. Patients with hypertension should not consume foods that contain a high amount of sodium such as canned foods, processed foods, and fast foods as the abundance of sodium can lead to the retention of fluid, which has a relation to blood pressure. Excessive salt keeps the amount of fluid in the body circulating higher than it should be, which means increased pressure on the walls of the blood vessels. Under the continued high pressure, the walls thicken and narrow, and the heart has to pump harder to move fluid around which results in the damage of the blood vessels and leads to the upsurge of blood pressure (Farquhar et al., 2015).

There are varieties of foods, but not all foods can be consumed by hypertension patients. However, a lot of them are subjected to sedentary lifestyles and find it difficult to withstand delicious, yet unhealthy local foods that trigger the increase of blood pressure. There must be a scientific way to identify the foods that can be consumed by hypertensives as well as the appropriate amount of food intake. Hence, this study implemented the Linear Programming (LP) and Integer Programming (IP) technique to formulate the mathematical model of diet planning for hypertension patients. This model determined the amount of nutrients needed as well as the cost of the food combination involved when the hypertension patient was given the optimal nutrients.

LP can be used as a tool to satisfy the amount of diets to nutritional and other additional constraints at once. Jerry Cornfield, who formulated "The Diet Problem" for the Army during World War II (1941-1945) in quest of a low-cost diet that would match a soldier's nutritional needs, initiated the hunt for diet solutions (Dooren, 2018). Several studies in diet planning problems have demonstrated the different targets of respondents such as chronic kidney patients, eczema patients and athletes (Malvar et al., 2021; Sheng \& Sufahani, 2018; Magdic et al., 2013). These studies take into consideration many factors in diets such as nutrients, the volume of food and the planned budget.

IP problem is a mathematical optimization that limits any or more of the variables to be an integer. Sheng \& Sufahani (2018) reported that the IP model is capable of producing an efficient and doable solution to these problems of the diet of an eczema patient. The research helped to explain the food needs of patients with eczema and the use of IP to achieve a prescribed and balanced diet. Besides, IP can be applied to

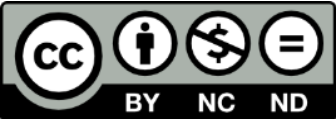

Copyright $\odot 2021$ UiTM Press. This is an open access article under the CC BY-NC-ND (https://creativecommons.org/licenses/by-nc-nd/4.0/) 
construct a mathematical model of a healthy balanced diet that minimizes daily calorie consumption and fulfills the required nutritional intake for youth (Jalil et al., 2017).

Paidipati et al. (2021) give some reliable methods to find the optimal menu planning using goal programming. They aimed to minimize the deviations of over and under achievements for appropriate meal menu selection with varying energy (calories) levels. Benvenuti et al. (2021) demonstrated the use of a multi-objective optimization model in designing two-week full-board menus for nursing homes.

\section{METHODOLOGY}

\section{Data Descriptions}

The research study is conducted prior to hypertension patients who age of 50s. The patient has varying kinds of dietary criteria including age, fitness level, medications, and others. The patient in this research is a 55-year-old-man with a history of Type 2 Diabetes Mellitus and hypertension for 10 years with BP (blood pressure) 160/90 $\mathrm{mmHg}$ and PR (pulse rate) of 88 beats/minute, $167 \mathrm{~cm}$ in height, $98 \mathrm{~kg}$ in weight, and considered as obese since his body mass index (BMI) is $35 \mathrm{~kg} / \mathrm{m}^{2}$. He also has a family history where his mother has diabetes and is currently on dialysis, while his father has a stroke with residual left hemiparesis. $\mathrm{He}$ is referred for further management of poorly controlled diabetes and hypertension as he has a sedentary lifestyle and an unhealthy diet. The relevant data were collected from a dietitian based in UiTM Medical Specialist Centre (UiTMMSC) Sungai Buloh.

The study focused on secondary data obtained from Standard Operation Procedure of Consulting Services for Individual with Hypertension and Recommended Nutrient Intakes for Malaysia (RNI) 2017. The data obtained consisted of the lower bound and upper bound of nutrient content requirements for hypertension patients. The nutrient involved in this study includes energy, protein, fat, carbohydrate, fibre, calcium, potassium, sodium, vitamin $\mathrm{C}$ and vitamin $\mathrm{B} 2$ which can be calculated based on the amount of energy.

Table 1: Values of Lower and Upper Bound of the 10 Nutrients

\begin{tabular}{|l|c|c|}
\hline \multicolumn{1}{|c|}{ Nutrients } & Lower Bound (LB) & Upper Bound (UB) \\
\hline Energy (kcal) & 2873.3 & - \\
\hline Protein $(\mathrm{g})$ & 431 & 574.66 \\
\hline Fat $(\mathrm{g})$ & 201.13 & 287.33 \\
\hline Carbohydrate $(\mathrm{g})$ & 1436.65 & 1723.98 \\
\hline Fibre $(\mathrm{g})$ & 20 & 30 \\
\hline Calcium $(\mathrm{mg})$ & 1000 & 1200 \\
\hline Potassium $(\mathrm{mg})$ & 3500 & - \\
\hline Sodium $(\mathrm{mg})$ & - & 2400 \\
\hline Vitamin C $(\mathrm{mg})$ & 70 & 2000 \\
\hline Vitamin B2 $(\mathrm{mg})$ & 1.3 & - \\
\hline
\end{tabular}

In this study, the food items that will be taken into the model only involve the list of foods in the Malaysian Food Composition Database Website. The food items are in standardized portion size and have been identified with their respective nutrient contents. The diet meal is designed in Malaysian style recipes. 


\section{Model Descriptions}

Linear Programming (LP) and Integer Programming (IP) are used to build and solve a problem using the menu planning model with 200 variables. The main objective of this study is to develop a mathematical model of diet planning for hypertension patients. The model also seeks to meet the optimal nutritional requirements depending on the recommended nutrient intakes. 10 nutrients were considered; energy, protein, fat, carbohydrate, fibre, calcium, potassium, sodium, vitamin C, and vitamin B2.

Furthermore, 10 types of foods are considered in this study, which are beverages, cereal-based meals, fish and seafood dishes, flour-based cereals, flour-based rice, flour-based wheat, fruits, meat dishes, miscellaneous, and vegetables. Every food category contributes specific dishes, so the food data comprised of 200 dishes were taken from the Malaysian Food Composition Database Website. The system planned a regular menu of breakfast meals, morning tea, lunch, dinner, evening tea and supper based on the data collected. This study uses LINGO software and Excel Solver to obtain the diet menu for hypertension patients by using LP and IP techniques, respectively. The objective functions and constraints are as follows:

Minimize the cost function:

$$
\begin{aligned}
& z=\sum_{i=1}^{200} a_{i} x_{i} \\
& z: \text { total daily meal prices } \\
& a_{i}: \text { cost of a food item } \\
& x_{i}: \text { the decision variables of food items } i
\end{aligned}
$$

10 nutrient requirements:

$$
l b \leq \sum_{i=1}^{200} b_{i j} x_{i} \leq u b, j=1,2,3, \ldots, 10
$$

$l b:$ the lower bound for nutrient $j$

$u b$ : the upper bound for nutrient $j$

$b_{i j}$ : the amount of nutrient $j$ in the food item $i$

$x_{i}:$ the decision variables of food items $i$

10 food groups:

$$
\begin{aligned}
& \sum_{i=1}^{10} e_{i} x_{i}=n \\
& e_{i}: \text { the food groups } \\
& x_{i}: \text { the decision variables of food items } i \\
& n: \text { the amount of requirements of a food group per day }
\end{aligned}
$$

Nonnegativity constraints:

$$
x_{i} \geq 0, \forall_{i}=1, \ldots, n
$$


Each type of food has its own selection of choices available. 200 food items from 10 food classes are meant for patients with hypertension per daily meal. 200 of the menu items taken from the Malaysian Food Composition Database Website, including beverages were considered in this study. The analysis considered 10 types of menu item groups. The selection of choices available for each category of menu items and the number of requirements per day is shown in Table 2.

Table 2: Food Requirement per Day

\begin{tabular}{|l|c|c|}
\hline \multicolumn{1}{|c|}{ Menu item groups } & Available range & Number of requirements per day \\
\hline Beverages & $x_{1}-x_{7}$ & 6 (including 2 plain water) \\
\hline Cereal-based meals & $x_{8}-x_{29}$ & 2 (including 1 cooked rice) \\
\hline Fish and seafood dishes & $x_{30}-x_{44}$ & 1 \\
\hline Flour-based cereals & $x_{45}-x_{64}$ & 1 \\
\hline Flour-based rice & $x_{65}-x_{88}$ & 1 \\
\hline Flour-based wheat & $x_{89}-x_{107}$ & 3 \\
\hline Fruits & $x_{108}-x_{133}$ & 2 \\
\hline Meat dishes & $x_{134}-x_{147}$ & 1 \\
\hline Miscellaneous & $x_{148}-x_{174}$ & 1 \\
\hline Vegetables & $x_{175}-x_{200}$ & 2 \\
\hline
\end{tabular}

In comparison, 20 menu items from 10 food groups are served in a day. The LP and IP model are built based on the data obtained. Subsequently, the food is arranged according to the breakfast, morning tea, lunch, evening tea, dinner, and supper as in Table 3.

Table 3: Menu Planning of Food Item per Day

\begin{tabular}{|l|l|c|}
\hline \multicolumn{1}{|c|}{ Meal } & \multicolumn{1}{|c|}{ Type of Food Group } & Amount of Serving \\
\hline \multirow{4}{*}{ Breakfast } & Beverages & 1 \\
\cline { 2 - 3 } & Flour-based cereal & 1 \\
\cline { 2 - 3 } & Flour-based wheat & 1 \\
\hline \multirow{4}{*}{ Lorning Tea } & Beverages & 1 \\
\cline { 2 - 3 } & Flour-based rice & 1 \\
\cline { 2 - 3 } & Flour-based wheat & 1 \\
\hline \multirow{5}{*}{ Evening Tea } & Beverages & 1 \\
\cline { 2 - 3 } & Cereal-based meal & 1 \\
\cline { 2 - 3 } & Vegetables & 1 \\
\cline { 2 - 3 } & Fruits & 1 \\
\cline { 2 - 3 } & Meat Dishes/Fish or Seafood Dishes & 1 \\
\hline \multirow{5}{*}{ Dinner } & Beverages & 1 \\
\cline { 2 - 3 } & Flour-based wheat & 1 \\
\cline { 2 - 3 } & Beverages & 1 \\
\cline { 2 - 3 } & Cereal-based meal & 1 \\
\cline { 2 - 3 } & Vegetables & 1 \\
\cline { 2 - 3 } & Fruits & 1 \\
\cline { 2 - 3 } & Meat Dishes/Fish or Seafood Dishes & 1 \\
\hline
\end{tabular}




\begin{tabular}{|l|l|c|}
\hline \multicolumn{1}{|c|}{ Meal } & \multicolumn{1}{|c|}{ Type of Food Group } & Amount of Serving \\
\hline \multirow{2}{*}{ Supper } & Beverages & 1 \\
\cline { 2 - 3 } & Miscellaneous & 1 \\
\hline & Total & $\mathbf{2 0}$ \\
\hline
\end{tabular}

\section{FINDINGS AND DISCUSSIONS}

Mathematical modelling is developed to serve as the optimal approach to diet problems for hypertension patients. The findings for LP and IP for a day meal preparation and nutrient intake can be seen in Table 4 and Table 5 respectively.

Table 4: Results of Linear Programming

\begin{tabular}{|c|c|c|}
\hline Meals & $\begin{array}{l}\text { Food Item } \\
\end{array}$ & Amount of Serving \\
\hline \multirow[t]{3}{*}{ Breakfast } & Milk, UHT, Chocolate Flavoured & 0.614 \\
\hline & Biscuit, Coconut & 0.524 \\
\hline & Kuih Apam Balik & 0.782 \\
\hline \multirow[t]{3}{*}{ Morning Tea } & Coconut Water & 0.715 \\
\hline & Kuih Bom & 1 \\
\hline & Kuih Apam & 1.654 \\
\hline \multirow[t]{5}{*}{ Lunch } & Plain Water & 1 \\
\hline & Rice, Chicken & 1 \\
\hline & Soya Bean Sprout ; Glycine Max & 0.823 \\
\hline & Papaya ; Carica Papaya & 1.659 \\
\hline & Spanish Mackerel, Fried & 0.875 \\
\hline \multirow[t]{2}{*}{ Evening Tea } & Sugar Cane, Juice & 0.873 \\
\hline & Doughnut & 1.04 \\
\hline \multirow[t]{5}{*}{ Dinner } & Plain Water & 1 \\
\hline & Rice, Cooked & 1 \\
\hline & Cauliflower ; Brassica Oleracea & 1.232 \\
\hline & Guava ; Psidium Guajava & 0.286 \\
\hline & Beef, Fried & 1.564 \\
\hline \multirow[t]{2}{*}{ Supper } & Milk, UHT, Low-Fat, Recombined & 1.798 \\
\hline & Rojak & 0.561 \\
\hline \multicolumn{2}{|c|}{ Total number of foods per day } & 20 \\
\hline \multicolumn{2}{|c|}{ Total cost (Ringgit Malaysia) } & 28.64 \\
\hline
\end{tabular}


Table 5: Results of Integer Programming

\begin{tabular}{|c|c|c|}
\hline Meals & $\begin{array}{l}\text { Food Item } \\
\end{array}$ & Amount of Serving \\
\hline \multirow[t]{3}{*}{ Breakfast } & Milk, UHT, Low-Fat, Recombined & 1 \\
\hline & Biscuit, Coconut & 1 \\
\hline & Kuih Apam & 1 \\
\hline \multirow[t]{3}{*}{ Morning Tea } & Sugar Cane, Juice & 1 \\
\hline & Kuih Bom & 1 \\
\hline & Kuih Apam & 1 \\
\hline \multirow[t]{5}{*}{ Lunch } & Plain Water & 1 \\
\hline & Rice, Cooked & 1 \\
\hline & Soya Bean Sprout ; Glycine Max & 1 \\
\hline & Guava ; Psidium Guajava & 1 \\
\hline & Spanish Mackerel, Fried & 1 \\
\hline \multirow[t]{2}{*}{ Evening Tea } & Milk, UHT, Chocolate Flavoured & 1 \\
\hline & Doughnut & 1 \\
\hline \multirow[t]{5}{*}{ Dinner } & Plain Water & 1 \\
\hline & Rice, Chicken & 1 \\
\hline & Cauliflower; Brassica Oleracea & 1 \\
\hline & Papaya ; Carica Papaya & 1 \\
\hline & Beef, Fried & 1 \\
\hline \multirow[t]{2}{*}{ Supper } & Sugar Cane, Juice & 1 \\
\hline & Rojak & 1 \\
\hline \multicolumn{2}{|c|}{ Total number of foods per day } & 20 \\
\hline \multicolumn{2}{|c|}{ Total cost (Ringgit Malaysia) } & 25.79 \\
\hline
\end{tabular}

A variety of meals are served daily, comprising six types of meals; breakfast, morning tea, lunch, evening tea, dinner, and supper. In addition, the regular diet meal contains beverages, cereal-based meals, fish and seafood dishes, flour-based cereals, flour-based rice, flour-based wheat, fruits, meat dishes, miscellaneous, and vegetables.

The cost increased marginally by using LP instead of IP. The amount of food created by the LP method is not possible to be eaten by patients. This is because it is difficult to determine the correct amount of food items to be taken since it is in non-binary values. IP is shown to be the best strategy or method for producing optimal solutions to the problem of diet.

\section{CONCLUSION AND RECOMMENDATIONS}

This study was conducted to build mathematical modelling of diet planning problem and hypertension patient has been chosen as a sample. Linear Programming and Integer Programming have been used as the methodology for this study. The cost of food combination using the LP approach is initiated as RM28.64. As for IP, the food combination with optimal nutrients needed costs RM25.79. Hence, from the findings, both of the mathematical modelling techniques can be used to find the cost of food combination with optimal nutrients needed by hypertension patients. Expenditure on the food menu can be reduced by applying the IP approach. In addition to maintaining a balanced diet that supplies both necessary minerals and vitamins, a viable alternative has also been identified for hypertension patients to prepare their diet menu according to a statistical model. IP provides a more practical approach for serving food products in whole (integer value). Expenditure rose marginally from RM25.79 to RM28.64 by using an IP instead of 
LP. This study helped to explain the food needs of patients with hypertension and the use of a LP and IP to achieve a considered and optimal diet. The mathematical model built in this analysis can also be a guideline for solving dietary issues for other organizations, such as the hospital, the university, and the training centre.

It is proposed that a study be performed with a greater sample size of food items so that one will be able to use LP and IP approaches to compare the findings of the method. Future researchers can also use a sample size of food items from different sources other than the list of food available in the Malaysian Food Composition Database Website. Further research can be undertaken to prepare a healthy diet menu that satisfies dietary criteria and is appropriate for patients with hypertension of all ages or any disorders requiring diet management. It is proposed that a comparative study be performed in further studies by using different methods other than LP and IP so that one will be able to use various approaches to compare findings of the diet planning problems.

\section{ACKNOWLEDGMENTS}

Special thanks to UiTM Medical Specialist Centre (UiTMMSC) Sungai Buloh.

\section{REFERENCES}

Benvenuti, L., De Santis, A. \& Cacchione, P. (2021). Multi-indicator design and assessment of sustainable diet plans. Journal of Cleaner Production, 313.

Dooren, C. V. (2018). A Review of the Use of Linear Programming to Optimize Diets, Nutritiously, Economically and Environmentally. Frontiers in Nutrition, 5. doi: 10.3389/fnut.2018.00048.

Farquhar, W., Edwards, D., Jurkovitz, C., \& Weintraub, W. (2015). Dietary Sodium and Health: More Than Just Blood Pressure. J Am Coll Cardiol., 1042-1050.

Institute for Medical Research, Kuala Lumpur. (1997). Retrieved from Malaysian Food Composition Database: https://myfcd.moh.gov.my/myfcd97/.

Jalil, N. D., Masrom, M., \& Wan Zakaria, W. (2017). A mathematical model of healthy diet menu plan for MARA Junior Science College boarding schools. Journal of Advanced Research Design, 8-14.

Magdić, D., Kljusurić, J. G., Matijević, L., \& Frketić, D. (2013). Analysis of diet optimization models for enabling conditions for hypertrophic muscle enlargement in athletes. Croat. J. Food Sci. Technol., $18-28$.

Malvar, R. J., Funtilar, J. H. F., Ibasan, M. J. I. \& Vite, J. J. L. M. (2021). Cost Optimization of Food Diet for Adult Filipino Patients with Stage 1 or Stage 2 chronic kidney diseases. Turkish Journal of Computer and Mathematics Education, 12, 5453-5459.

Paidipati, K. K., Komaragiri, H. \& Chesneau, C. (2021). Pre-Emptive and Non-Pre-Emptive Goal Programming Problems for Optimal Menu Planning in Diet Management of Indian Diabetes Mellitus Patients. International Journal of Environmental Research and Public Health, 18. 
Recommended Nutrient Intakes for Malaysia. (2017). National Coordinating Committee on Food and Nutrition, Ministry of Health.

Sheng, L. Z., \& Sufahani, S. (2018). Optimal Diet Planning for Eczema Patient Using Integer Programming. Journal of Physics: Conference Series (pp. 1-8). IOP Publishing.

Sheng, L. Z., Sufahani, S., \& Ismail, Z. (2017). Mathematical modelling technique for diet planning problem: Eczema patient. International Journal of Multidisciplinary Research and Development, 36-39.

Standard Operation Procedure of Consulting Services for Individual with Hypertension. (2014). Bahagian Sains Kesihatan Bersekutu, Kementerian Kesihatan Malaysia.

WHO. (April, 2013). A Global Brief on Hypertension. Silent Killer, Global Public. Retrieved from World Health Organization 2013: https://www.who.int/cardiovascular_diseases/publications/global_brief_hypertension/en/ 